\title{
Retour sur « Travail et technique chez les Grecs »
}

\section{Gil Bartholeyns}

\section{OpenEdition}

Journals

Édition électronique

URL : https://journals.openedition.org/tc/5213

DOI : $10.4000 /$ tc. 5213

ISSN : 1952-420X

Éditeur

Éditions de l'EHESS

Édition imprimée

Date de publication : 30 juin 2010

Pagination : 332-334

ISSN : 0248-6016

\section{Référence électronique}

Gil Bartholeyns, « Retour sur «Travail et technique chez les Grecs »», Techniques \& Culture [En ligne], 54-55 | 2010, mis en ligne le 30 janvier 2013, consulté le 29 septembre 2022. URL : http:// journals.openedition.org/tc/5213; DOI : https://doi.org/10.4000/tc.5213 


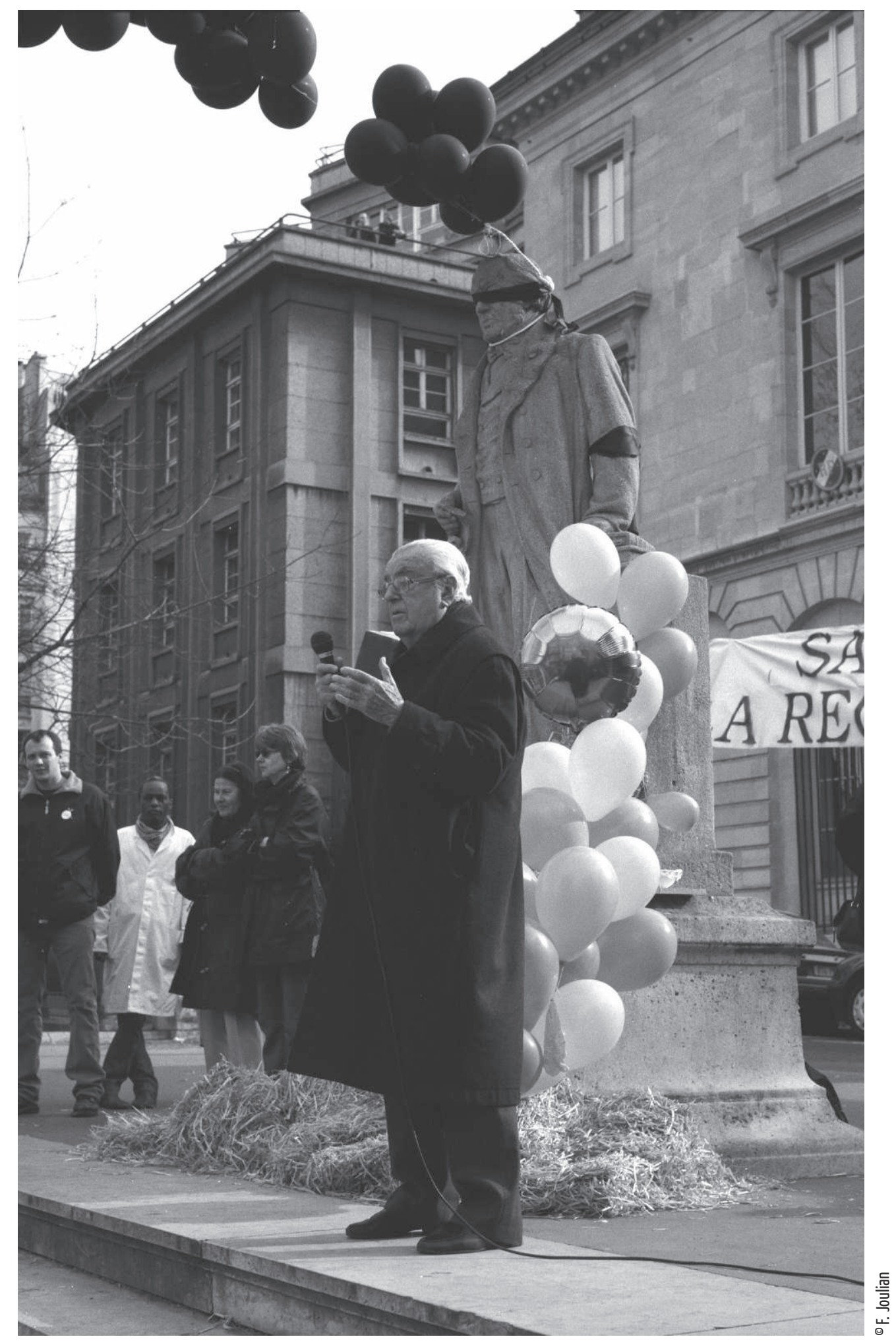




\section{Retour sur}

\section{«Travail et technique chez les Grecs »}

Le monde grec antique, en raison de sa proximité supposée avec nos habitudes de penser et de sentir, nous dit Charles Kanelopoulos, a longtemps résisté à l'approche ethnographique qui a pour objet la découverte de l'Autre. Les Grecs étant nos frères sinon nos pères spirituels que seul le temps nous empêcherait de toucher, l'étude de leur univers serait incompatible avec une démarche anthropologique. Voilà l'espèce d'exception dans laquelle on tenait les Grecs avant de les « indigéniser ». En réalité, il en allait de même pour toutes les périodes de l'histoire européenne : non seulement pour l'Antiquité grécoromaine, mais plus encore peut-être pour l'Occident médiéval et l'Europe préindustrielle. Car, dans une large mesure en effet, c'est grâce aux spécialistes des mondes antiques tels que Louis Gernet et à sa suite Jean-Pierre Vernant, Marcel Détienne ${ }^{1}$, Pierre VidalNaquet (1979) ou Paul Veyne, que la révolution « anthropologique » de la pensée historienne de la culture occidentale a pu avoir lieu à partir des années 1960 (Bartholeyns, 2010). Cela peut sembler tardif aux yeux d'un ethnologue, mais c'est précoce du point de vue de l'historien.

L'histoire antique est même un des « terrains » à partir desquels va se diffuser, parmi les historiens des autres périodes, l'intérêt pour le mythe (Schmitt 1988), la parenté, la technique ou la technologie. L'immense valeur du travail de Vernant (1952, 1955, 1956, 1957) est d'avoir ainsi déplacé l'attention portée jusque-là aux seuls aspects concrets et archéologiques de la culture matérielle, particulièrement étudiés pour les périodes rares en documents écrits, vers les dimensions culturelles de la technique. C'est-à-dire la valeur du geste technique ; la question du travail ; le statut des techniciens et des créateurs (artisans, mécaniciens, ingénieurs) ; les origines mythiques des savoir-faire (Prométhée, Hermès, etc.) ; enfin, les mots et catégories de pensée de l'action des hommes sur la matière. Notamment la tekhnê, ou cet art propre du médecin, du menuisier ou de l'orateur. 
La mètis, ou la ruse d'adaptation face aux contraintes matérielles et techniques, qui fait tant penser que les grecs ont conceptualisé à leur manière la «pensée sauvage » par laquelle Claude Lévi-Strauss (1962) cherchait à décrire la raison pratique universellement distribuée parmi les hommes. Mais encore les notions de progrès, d'œuvre (ergon), de nature, d'action (praxis), de production (poièsis), ou l'absence de tout terme pour désigner ce que nous entendons par «travail ». En fin de compte, plus rien chez les Grecs, après la lecture de Vernant, ne va de soi pour notre regard contemporain. L'historicisation est fondamentalement ici une opération ethnographique.

D’une société jugée si proche qu'elle semblait d'abord exclure toute mise à distance, nous sommes passés à un monde à ce point exotique qu'on en vient à questionner la nature voire l'ampleur ou la continuité de l'héritage grec, par-delà l'apport germanique et plus de quinze siècles de christianisme. Que dire de nos attitudes à l'égard des objets techniques ou du travail manuel ? Nous sommes du moins invités à supposer que nos familiarités sont des « inévidences » totales. Le texte qu'on va lire contribuait à faire prendre conscience au moment de sa parution, en 1992, et il nous apprend encore aujourd'hui, presque en toute fraîcheur, qu'un tournant épistémologique avait eu lieu chez les historiens, après quoi la technologie, la science, les savoirs pratiques ne pourraient plus jamais être abordés en Afrique, en Océanie ou en Amazonie par un Européen sans qu'il ne tienne compte, en même temps, de son propre rapport à la technique. Ce rapport est comme une lentille à travers laquelle se donnent les gestes, les objets et la pensée technicienne des autres.

Les techniques des sociétés qu'étudie l'ethnologue ne se détachent jamais sur le fond blanc et neutre, éternel et stable de la perception de l'observateur. Aussi n'est-ce pas tant Gilbert Simondon (1958), Maurice Daumas (1962) ou même Marcel Mauss (1950 [1936], 1967 [1947], Schlanger (2006), que Jean-Pierre Vernant et les études pionnières ou pointues de Peter Sternagel (1966), Jacques Le Goff (1971), Elspeth Whitney (1990), Jean-Claude Schmitt (1990) ou Ruedi Imbach (2002) pour l'Occident chrétien, et pour l'époque classique et moderne, de Jacques Guillerme et Jan Sebestik (1966) ou d'Antoine Picon (1992), qui, en dénaturalisant avec force le point de vue du chercheur européen, offrent les bases de l'objectivité réflexive dont tout technologue doit impérativement s'armer, qu'il s'intéresse au monde contemporain ou aux sociétés traditionnelles. L'existence même de la sociologie des sciences, telle qu'elle a pu être développée par Bruno Latour par exemple (depuis 1979 puis 1987), ou la présence d'un texte de synthèse sur la pensée technique des Grecs dans la revue Techniques \& Culture, est la poursuite de cette « déstabilisation » du statut occidental moderne de la technique et de l'artefact entamée par les historiens. Si bien qu'on assiste à des prochronismes méthodologiques quand certaines catégories de pensée ou conceptions anciennes, comme la mètis en l'occurrence, sont réinvesties dans le cadre d'ethnographies contemporaines ou de recherches sur la nature du travail artisanal (e.g. Schwint 2002, 2005).

L'essai dense et limpide que Charles Kanelopoulos consacre à l'œuvre de Jean-Pierre Vernant montre l'affinité cruciale de l'ethnologue et de l'historien pour l'étude des cultures matérielles. Les terrains respectifs de l'un et de l'autre, désormais, se ressemblent beaucoup. Mais surtout, les résultats du travail historique ont contribuéà transformer l'anthropologie des techniques. 